\title{
Antioxidant potential, biochemical activity and hypoglycemic effects of $R$. obtusifolius L. seed extracts used in Armenian traditional medicine
}

\author{
Mikayel Ginovyan*, Naira Sahakyan, Anush Aghajanyan, and Armen Trchounian \\ Department of Biochemistry, Microbiology \& Biotechnology Yerevan State University, Yerevan, Armenia
}

\begin{abstract}
The diversity of plants in Armenia is due to the singularity of natural environment. However, biochemical activity of these plants has not been studied well. The goal was to investigate biological activities as well as antihyperglycemic properties of Rumex obtusifolius L. in rabbits with hyperglycemia. According to obtained data, $R$. obtusifolius extracts possessed high antioxidant activity in chemical-based tests. GS/MS analysis of its methanol extracts allowed identification of several compounds, which could have high contribution on biological activities. The sub-cytotoxic concentration of investigated extract was $10 \mathrm{mgmL}^{-1}$ on Murine microglial BV-2 WT cell lines. Oral administration of ethanol extract showed significant effect on hyperglycemia, reducing fasting glucose levels $(57.3 \%, \mathrm{p}<0.05)$ and improving glucose tolerance. These findings suggest that $R$. obtusifolius extracts could be source of new biologically active compounds and recommended for treatment of diabetes mellitus.
\end{abstract}

\section{Introduction}

Armenia is positioned at the junction of several biogeographical zones and appears to be rich in health promoting edible or medicinal plants. These zones are closely linked, resulting in relatively few endemic species of Armenian flora. Overall, 123 endemic plant species are described. These plants are commonly employed in traditional medicine for the prevention and treatment of various diseases from the 15th century and even earlier time. The privilege is the less cytotoxicity of plants to the humans. Armenian flora is rich with with herb species which have been widely used in traditional medicine since ancient times [1]. However, this biodiversity was not studied properly for their biological activities, biochemical properties, including antioxidant properties [2], and hypoglycemic activities [3]. Therefore, there could be hidden a great potential for their antioxidant properties and antihyperglycemic effects which can has huge value for therapeutic uses, as well as food industry [4].

The aim of this research was to evaluate antioxidant potential of crude extracts of R. obtusifolius, identify biologically active compounds using GC-MS technique and to investigate biochemical properties and antihyperglycemic properties of R. obtusifolius alcohol extract in rabbits with hyperglycemia.

\section{Materials and methods}

\subsection{Plant materials}

Collection of plant material and preparation of plant crude extracts $R$. obtusifolius L. (seed) samples (voucher specimen number ERCB 13208) were collected from Tavush region (1300-1600 $\mathrm{m}$ above sea level). The collection, identification and preparation of plant material was done according to already established protocol [1]. $R$. obtusifolius L. samples were deposited to the Herbarium of Yerevan State University. Plant crude extracts were prepared by maceration technique using methanol (98\%), ethanol $(96 \%)$ and acetone $(99.8 \%)$, according to method described previously [1]. Dry crude extracts stored in freezer $\left(-18-20{ }^{0} \mathrm{C}\right)$. For determination of hypoglycemic properties, the dried seeds were extracted with $40 \%$ ethanol for $20 \mathrm{~min}$ at $60^{\circ} \mathrm{C}$. Briefly, $270-280 \mathrm{mg}$ of dry matter are in $6 \mathrm{ml}$ of ethanol. The extract was filtered with Watman filter paper (N1, Unichem, China) and after cooling at room temperature was orally administrated.

\subsection{Evaluation of antiradical activity by DPPH assay}

Antiradical activity of tested plant crude extracts was evaluated by using 2,2-diphenyl-1-picrylhydrazyl (DPPH) assay [5]. Test solutions contained $250 \mu \mathrm{L}(1$ $\mathrm{mM}) \mathrm{DPPH}, 750 \mu \mathrm{L}$ ethanol (96\%) and $1000 \mu \mathrm{L}$ plant crude extract with different concentrations. Catechin was used as positive control. $\mathrm{IC}_{50}$ values for each plant extract were determined.

\subsection{Hydrogen peroxide reducing activity}

Hydrogen peroxide $\left(\mathrm{H}_{2} \mathrm{O}_{2}\right)$ reducing ability of $R$. obtusifolius was evaluated by the method described by Ruch et al.[6]. Percent reduction of hydrogen peroxide 
calculated by following formula: $\mathrm{H}_{2} \mathrm{O}_{2}$ reduction $=\mathrm{A}_{\mathrm{c}^{-}}$ $A_{t} / A_{c} \cdot 100 \%$ where $A_{c}$ - absorption of control solution, $A_{t}$ - absorption of test solution. Ascorbic acid was used as positive control at $10 \mu \mathrm{g} \mathrm{mL} \mathrm{L}^{-1}$ concentration."

\subsection{Metal chelating activity}

Metal chelating activity of $R$. obtusifolius extracts was assessed by color change due to the formation of ferrozine- $\mathrm{Fe}^{2+}$ complexes [7]. Percent metal chelating activity of plant extracts was calculated according the following formula:

$$
\text { Chelating activity }=\frac{A c-A t}{A c} * 100 \%
$$

where $A_{c}$ - absorption of control solution, $A_{t}$ - absorption of test solution. EDTA was used as a positive control at $22 \mu \mathrm{g} \cdot \mathrm{mL}^{-1}$ concentration.

\subsection{Determination of extent of lipid peroxidation}

TBARs assay was used for evaluation of $R$. obtusifolius extracts on extent of lipid peroxidation[8]. Mice brain tissue homogenate (in $20 \mathrm{mM}$ phosphate buffer ( $\mathrm{pH}$ 7.4)) used during the test. Test solution contains $0.3 \mathrm{~mL}$ of plant extract ( $3 \mathrm{mg} / \mathrm{mL}$ concentration), $0.7 \mathrm{~mL} 250 \mathrm{mM} \mathrm{HCl}, 1$ $\mathrm{mL}$ tissue homogenate and $2 \mathrm{~mL}$ TBA solution $(0.375 \%)$. The absorbance of mixtures measured at $532 \mathrm{~nm}$. Malondialdehyde concentration calculated using an extinction coefficient of $1.56 \cdot 10^{5} \mathrm{M}^{-1} \mathrm{~cm}^{-1}$.

\subsection{BV-2 microglia cell culture}

Murine microglial BV-2 WT cell lines were grown in a $5 \% \mathrm{CO}_{2}$ incubator at $37{ }^{\circ} \mathrm{C}$ in Dulbecco's modified Eagle medium (DMEM) supplemented with $10 \%(v / v)$ heat inactivated fetal bovine serum (FBS) and $1 \%$ antibiotics (penicillin, streptomycin); culture medium was changed every 2 days. BV-2 cells were seeded on 96-well microplates at $25 \cdot 10^{4}$ cells per well for viability assay.

\subsection{MTT assay}

The cell proliferation and/or mitochondrial activity were measured using 3-(4,5-dimethyltrazol-2-yl)-2,5diphenyltetrazolium bromide (MTT) assay. Cells, plated in 96-wells plates, were treated for 24-72 $\mathrm{h}$ with different concentrations of extracts $\left(50-5 \cdot 10^{-4} \mu \mathrm{L} \cdot \mathrm{mL}^{-1}\right.$ in dimethyl sulfoxide. Cells were incubated for $2 \mathrm{~h}$ with MTT dye followed by the absorbance (Abs) measurement at the $570 \mathrm{~nm}$ with a microplate reader and the subcytotoxic concentration was selected for further investigations [9]. The MTT test was carried out in order to clarify the influence of $R$. obtusifolius crude methanol extract cell viability.

\subsection{Identification of volatile compounds by GC- MS technique}

For identification of volatile compounds contained in $R$. obtusifolius crude methanol extract, GC-MS technique was applied using a Hewlett-Packard 5890 Series II gas chromatograph, fitted with a fused silica HP - 5MS capillary column $(30 \mathrm{~m} \times 0.25 \mathrm{~mm}$, in thickness $0.25 \mu \mathrm{m})$ [10], The identification of peaks was tentatively carried out based on library search using National Institute of Standards and Technology (NIST)-2013.

\subsection{Induction of hyperglycemia in experimental rabbits and blood sampling}

The domestic rabbits (Oryctolagus cuniculus domesticus) (1800-1900g) were divided into three groups $(n=9)$ as follows: group 1: normoglycemic, group 2: hyperglycemic control, putting immobilization, and group 3: hyperglycemic experimental, in common with immobilization received $R$. obtusifolius seed extract (150 $\mathrm{mg} \mathrm{kg}^{-1}$ body weight.). Hyperglycemia was induced by immobilization stress in the rabbits during 21 days ( 5 $\mathrm{h}$ daily) [11]. The animals were authorized by the "International Recommendation on Carrying out of Biomedical Researches with use of Animals," and the study plan has been approved by the National Center of Bioethics (Armenia).

\subsection{Biochemical Analysis}

Blood samples were taken from the aural vein and collected in serum separation tubes (Clot Activator \& Gel, Turkey). Blood clot was removed by centrifugation at $3000 \mathrm{~g}$ for $10 \mathrm{~min}$ in a centrifuge at $4^{\circ} \mathrm{C}$. The resulting supernatant was designated as a serum. The biochemical analysis was performed to measure the serum level of glucose, total cholesterol (TC), high-density lipoprotein (HDL), low-density lipoprotein (LDL), and triglycerides (TG). All parameters were assayed using enzymatic kit. Serum glucose level ( $\mathrm{mmol} / \mathrm{L})$ was determined using glucose test kit based on the glucose oxidase method [12]. TC and TG were estimated by the method, as described [12]HDL and LDL were measured using the method, as described [13]. Analytical tests were conducted using automatic biochemical analyzers VITROS-5.1/FS (Germany) and MINDRAY B1-120 (China).

\subsection{Oral Glucose Tolerance Test}

On the $10^{\text {th }}$ day of treatment an oral glucose tolerance test (OGTT) was carried out. Animals were fasted overnight before commencing of experiments. $20 \%$ glucose solution ( $2 \mathrm{~g} \mathrm{~kg}^{-1}$ b.w.) was administrated a signal oral dose to all groups of rabbits. The blood glucose level was measured by portable glucometer (Contour TS, Bayer, Switzerland). Blood samples were collected from aural vein at $0,30,60$, 90, and 120 min after glucose loading.

\footnotetext{
*Corresponding author: mikayel.ginovyan@ysu.am
} 


\subsection{Data processing}

All experiments were independently repeated at least 3 times. Obtained data were processed; mean values and standard deviations were calculated using GraphPad Prism 8.0.1 (GraphPad Software, Inc.; USA) software. The results obtained in the study are reliable $(\mathrm{p}<0.05)$, unless another value is followed.

\section{Results and Discussion}

$R$. obtusifolius or broad-leaved dock is well known herb which have been widely used in traditional medicine from ancient times for treatment of infectious diseases, skin rash, mucosal inflammations, etc.[14]. In previous research works of our group, promising antimicrobial, antibiotic modulatory, and antiviral activity of its crude extracts was shown $[1,15]$. TLC-bioautographic analysis allowed separating active antimicrobial fractions from $\mathrm{R}$. obtusifolius extracts against Staphylococcus aureus MDC 5233 and describing the chemical nature of those compounds [14]. It was hypothesized, that polar compounds could have considerable contribution to the antibacterial activity of acetone and methanol extracts of R. obtusifolius[14].

In current research based on chemical tests it was shown that crude methanol and acetone extracts of seeds of $R$. obtusifolius possessed promising antioxidant activity. Particularly high DPPH, hydrogen peroxide reducing and metal chelating activity were shown (Table I). It was revealed that methanol extract of R. obtusifolius had $25.29 \mu \mathrm{g} \mathrm{mL}-1$ IC50 value in the presence of DPPH $0.05 \mathrm{mg} \mathrm{mL}-1$ concentration. It was shown that at the presence of $100 \mu \mathrm{g} \mathrm{mL}-1$ concentration R. obtusifolius acetone extracts have $99.30 \%$ hydrogen peroxide reducing activity when the concentration of $\mathrm{H} 2 \mathrm{O} 2$ in the mixture was $36 \mathrm{mM}$. Its methanol extract exhibited moderate activity leading to $40.78 \%$ hydrogen peroxide reduction. On the other hand, $\mathrm{R}$. obtusifolius methanol extracts exhibited expressed metal chelating activity as well at the concentration of $125 \mu \mathrm{g} \mathrm{mL}-1$ by reducing the number of $\mathrm{Fe} 2+$-ferrozine complexes by $73.02 \%$ at the presence of $0.125 \mathrm{mM} \mathrm{FeCl} 2$. Its acetone extract had low metal chelating ability at tested concentrations. TBARs assay revealed that $\mathrm{R}$. obtusifolius methanol and ethanol extracts have not possessed anti-peroxidative activity till $225 \mu \mathrm{g}$ mL-1 concentration.

\subsection{GC-MS Analysis of R. obtusifolius methanol extract.}

In order to identify biologically active volatile and semivolatile constituents $R$. obtusifolius methanol extract GCMS technique was used. Based on obtained data various biologically active compounds were identified, which could play important role in their antioxidant effect. In general, 21 compounds were identified in methanol extract of $R$. obtusifolius. The identified compounds and their characteristics are shown in Table II. Some of the identified compounds are considered to possess biological activities. These were linoleic acid (41.32\%), cis-vaccenic acid $(24.43 \%)$, palmitic acid $(12.25 \%)$, oleic acid $(3.65 \%)$ 1,2,4-benzenetriol(0.46\%), N-[4-bromo-n-butyl]-2piperidinone $(0.64 \%)$ which present in the extracts with relatively high concentrations and have different biological activities based on literature data [16,17]. These compounds could have a contribution to the antioxidant and antimicrobial activities of this plant extracts. Other bioactive compounds also identified in the extract but only at low concentrations (Table 2).

\subsection{The effect of R. obtusifolius methanol extract on BV2 cell viability (MTT assay)}

According to this test the sub-cytotoxic concentration of investigated extract was $10 \mathrm{mgmL}^{-1}$ (Fig. 1) $(p<0.05)$.

\subsection{Effect of R. obtusifolius on Fasting Glucose Levels.}

Antihyperglycemic activity of $R$. obtusifolius seeds ethanol extract was evaluated on hyperglycemic rabbit model. Fasting blood glucose levels in the hyperglycemic control $(56.2 \%)$ and hyperglycemic $+R$. obtusifolius extract $(48.0 \%)$ groups during the first day of immobilization were significantly increased, compared to the normoglycemic group, $\mathrm{p}<0.05$ (Fig. 2).

Therefore, it may be noted that disposable strong stressful pressure provokes of hyperglycemia. Treatment with $R$. obtusifolius $(150 \mathrm{mg} / \mathrm{kg} \mathrm{BW})$ single dose for 21 days showed a significant reduction in fasting glucose to hyperglycemic rabbits $(57.3 \%, \mathrm{p}<0.05)$ in comparison with $1^{\text {th }}$ day value.

\subsection{Effect of R. obtusifolius on OGTT}

The results of effect on OGTT were observed that the seeds extract showed a significant effect on hyperglycemia compared to the hyperglycemic group (Fig.3).

Blood glucose in all groups were increased at $30 \mathrm{~min}$ time point after glucose load, and then gradually decreased. following hours. At $120 \mathrm{~min}$ blood glucose levels were significantly reduced in treated group of rabbits $(25.3 \%)$ and hyperglycemic control group (14.7\%) compared to the values at $30 \mathrm{~min}$. Therefore, glucose tolerance was significantly improved in the $R$. obtusifolius treated animal groups, when compared to the hyperglycemic control group $(\mathrm{p}<0.05)$.

\subsection{Effect of Ethanol Extract of R. obtusifolius on Serum Lipid Profiles}

The data of effect of $R$. obtusifolius ethanol extract on serum lipid profiles showed that the TC and LDLcholesterol levels in the hyperglycemic control group were significantly increased $(68.8 \%$ and $61.9 \%$ respectively), TG level was increased (17.5\%) compared to the normoglycemic group (Table III). After 21 days of oral treatment, physiological levels of blood lipids parameters demonstrated significantly decreased TC and LDL-cholesterol levels (53.3\% and $38.4 \%$, respectively), 
and reduced TG level (17.5\%) compared to the hyperglycemic control group. The HDL levels of the extract treated hyperglycemic group did not differ significantly from the hyperglycemic animals group.
Although the hyperglycemic control group of animals demonstrated a tendency towards increased LDLcholesterol level compared to the other groups.

Table 1. Antioxidant activity of the tested plant methanol and acetone extracts using different chemical based methods

\begin{tabular}{|c|c|c|c|c|c|}
\hline Plant name & Extract & $\begin{array}{c}\text { DPPH }^{*} \\
\text { reduction } \mathrm{IC}_{50} \\
\text { value }\left(\mu \mathrm{g} \mathrm{mL}^{-1}\right)\end{array}$ & $\begin{array}{l}\mathrm{H}_{2} \mathrm{O}_{2} \% \text {-reduction in the } \\
\text { presence of } 100 \mu \mathrm{g} \mathrm{mL}^{-1} \\
\text { plant crude extract }\end{array}$ & $\begin{array}{c}\mathrm{Fe}^{2+} \% \text { chelation in the } \\
\text { presence of } 100 \mu \mathrm{g} \\
\mathrm{mL}^{-1} \text { plant crude } \\
\text { extract }\end{array}$ & $\begin{array}{l}\text { MDA \% reduction in } \\
\text { the presence of } 225 \mu \mathrm{g} \\
\mathrm{mL}^{-1} \text { plant crude extract }\end{array}$ \\
\hline \multirow[t]{2}{*}{ R. obtusifolius } & Methanol & $25.29 \pm 0.8$ & $40.78 \pm 0.9$ & $73.02 \pm 1.6$ & $-*$ \\
\hline & Acetone & ND** & $99.30 \pm 2.1$ & $5.56 \pm 1.0$ & - \\
\hline Positive control & & 3 (Catechin) & $\begin{array}{c}11.23 \pm 0.9 \text { (Ascorbic } \\
\text { acid) }\end{array}$ & $\begin{array}{l}28.57 \pm 2.1 \\
(\text { EDTA)*** }\end{array}$ & $91.1 \pm 1.4$ (Tocopherol) \\
\hline
\end{tabular}

*absence of activity, **ND - not determined, *** EDTA -Ethylene diamine tetraacetic acid. All experiments were independently repeated three times. Average means with standard deviations are represented, $\mathrm{p}<0.05$.

Table 2. Compounds identified in the crude extract of R. Obtusifolius

\begin{tabular}{|c|c|c|c|c|}
\hline Identified compound & $\mathrm{RT}^{*}$ & $\begin{array}{c}\% \text { Peak } \\
\text { area }\end{array}$ & Compound nature & Biological activities \\
\hline 1,2,4-Benzenetriol & 15.540 & 0.46 & phenolics & $\begin{array}{l}\text { Antiseptic, fungicidal, insecticide, } \\
\text { antioxidant }\end{array}$ \\
\hline Tritetracontane & 19.703 & 0.12 & alkane & Insecticide \\
\hline Hexadecanoic acid, methyl ester & 21.619 & 0.30 & $\begin{array}{c}\text { fatty acid methyl } \\
\text { esters }\end{array}$ & Antioxidant, pesticidal, antinematodal \\
\hline $\begin{array}{c}\text { 1,2-Benzenedicarboxylic acid, } \\
\text { butyl } 2 \text {-methylpropyl ester } \\
\text { (Butyl isobutyl phthalate) }\end{array}$ & 21.893 & 0.54 & - & Not reported \\
\hline Palmitic acid & 22.572 & 12.25 & fatty acid & $\begin{array}{c}\text { Antibacterial, antioxidant, pesticidal, } \\
\text { antinematodal }\end{array}$ \\
\hline Hexadecanoic acid, ethyl ester & 22.879 & 1.29 & $\begin{array}{c}\text { fatty acid ethyl } \\
\text { esters }\end{array}$ & $\begin{array}{c}\text { Antioxidant, anti-nematodal, pesticidal, } \\
\text { hemolytic }\end{array}$ \\
\hline Eicosane & 23.251 & 0.19 & alkane & Not reported \\
\hline Oleic Acid & 24.018 & 3.65 & fatty acid & Antimicrobial \\
\hline Methyl linoleate & 24.686 & 0.45 & fatty acid & Antifungal, antitumor \\
\hline $\begin{array}{c}\text { 11-Octadecenoic acid, methyl } \\
\text { ester }\end{array}$ & 24.850 & 0.68 & $\begin{array}{c}\text { fatty acid methyl } \\
\text { esters }\end{array}$ & Not reported \\
\hline 3,8-Dimethyldecane & 25.168 & 0.16 & alkane & Not reported \\
\hline Linoleic acid & 26.022 & 41.32 & fatty acid & Antibacterial \\
\hline cis-Vaccenic acid & 26.209 & 24.43 & fatty acid & Antimicrobial \\
\hline 4-Methyldocosane & 29.11 & 0.15 & alkane & Not reported \\
\hline $\begin{array}{l}\text { N-[4-bromo-n-butyl]- 2- } \\
\text { Piperidinone }\end{array}$ & 31.050 & 0.64 & alkaloids & Antimicrobial, antioxidant, anti-inflammatory \\
\hline 1-Heptadecene & 32.923 & 0.32 & alkenes & Not reported \\
\hline cis-9-Hexadecenoic acid & 33.668 & 0.40 & fatty acid & Antibacterial \\
\hline Octadecane & 34.204 & 0.27 & alkane & Not reported \\
\hline 9-Octadecenal, (Z)- & 34.872 & 0.53 & fatty aldehydes & Antimicrobial \\
\hline Heptacosane, 1-chloro- & 35.190 & 0.31 & & Not reported \\
\hline Supraene & 36.351 & 0.21 & triterpenoids & $\begin{array}{c}\text { Antibacterial, antioxidant, pesticidal, } \\
\text { antitumor }\end{array}$ \\
\hline None pure ingredients & & 2.58 & & \\
\hline
\end{tabular}




\section{R. obtusifolius}

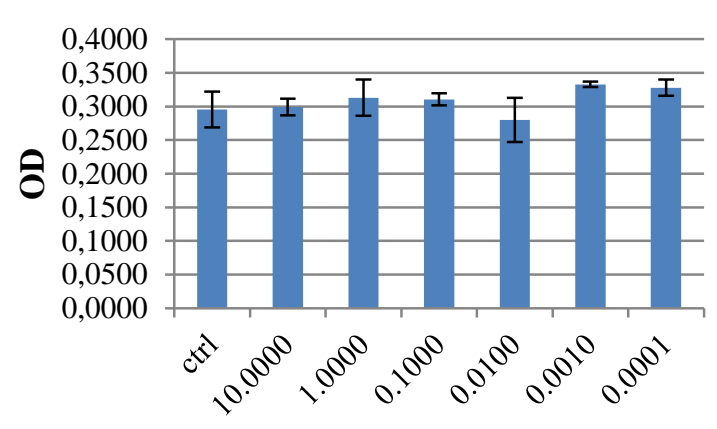

concentrations $\mathbf{m g} / \mathbf{m L}$

Fig. 1. Effects of R. obtusifolius extract on viability of BV-2 WT (MTT assay). Cells were treated for $24 \mathrm{~h}$ with extract at different concentrations $\left(50\right.$ to $\left.10^{-4} \mathrm{mgmL}^{-1}\right)$. The results represent the mean $\pm \mathrm{SD}$ of the three repetitions. Values are given as average of the repetitions. The significance is presented with the Student-t test: $p<0.05$.

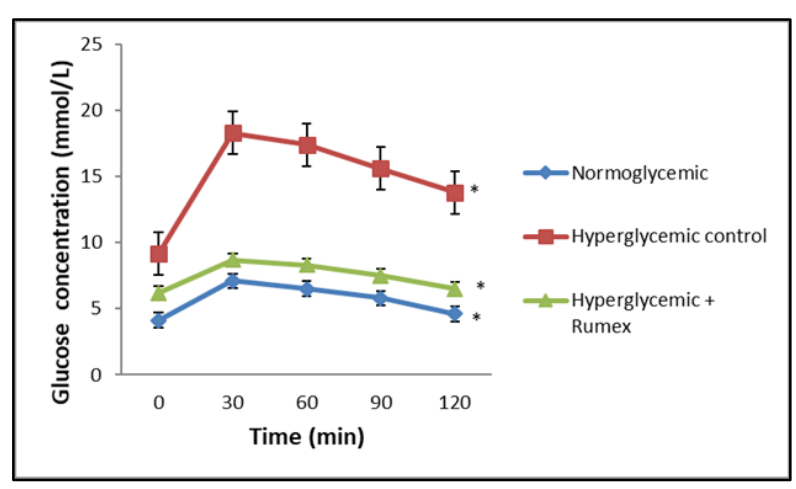

Fig. 2. Effect $R$. obtusifolius ethanol extract on OGTT in normoglycemic and hyperglycemic rabbits. Data are represented as mean \pm SD for 3 animals per group. $*$ Significantly different levels compared to the normoglycemic group. The significance is presented with the Student-t test: $p<$ 0.05 .

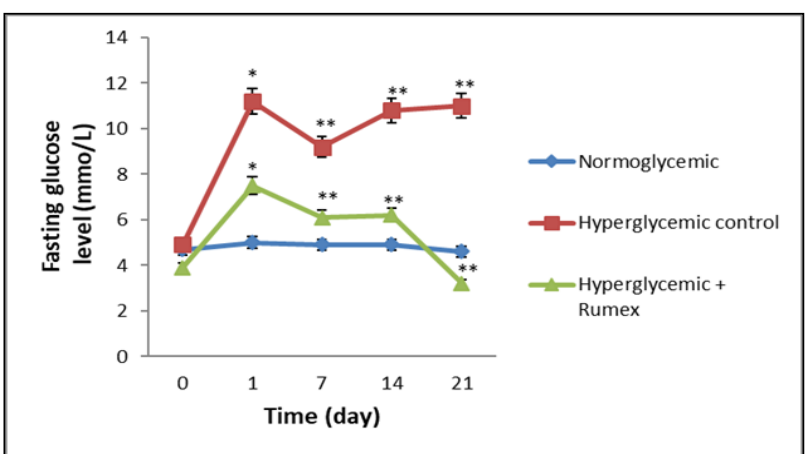

Fig.3 Effect of $R$. obtusifolius ethanol extract on fasting blood glucose levels in normoglycemic and hyperglycemic rabbits. Data are represented as mean \pm SD for 3 animals per group. $*$ Significantly different levels compared to the nonhyperglycemic group. $* *$ Significantly different levels compared to the hyperglycemic control group. The significance is presented with the Student-t test: $\mathrm{p}<0.05$.
Table 3. The effects of SR aqueous extracts on Serum lipids in rabbits

\begin{tabular}{|c|c|c|c|}
\hline \multirow{2}{*}{$\begin{array}{c}\text { Parameters } \\
\left(\mathrm{mmol} \mathrm{L}^{-1}\right)\end{array}$} & \multicolumn{3}{|c|}{ Experimental groups of animals } \\
\cline { 2 - 4 } & Normoglycemic & $\begin{array}{c}\text { Hyperglycemic } \\
\text { control }\end{array}$ & $\begin{array}{c}\text { Hyperglycemic } \\
+ \\
\text { R.obtusifolius }\end{array}$ \\
\hline TC & $1.4 \pm 0.08$ & $4.5 \pm 0.16^{*}$ & $2.1 \pm 0.09^{* *}$ \\
\hline TG & $0.85 \pm 0.12$ & $1.03 \pm 0.4^{*}$ & $0.85 \pm 0.05^{* *}$ \\
\hline HDL & $0.78 \pm 0.04$ & $1.02 \pm 0.15^{*}$ & $1.04 \pm 0.08^{* *}$ \\
\hline LDL & $1.0 \pm 0.15$ & $2.63 \pm 0.09^{*}$ & $1, .62 \pm 0.08^{* *}$ \\
\hline VLDL & $0.17 \pm 0.03$ & $0.46 \pm 0.07^{*}$ & $0.38 \pm 0.02^{* *}$ \\
\hline
\end{tabular}

$*$ Significantly different from normoglycemic group $(\mathrm{p}<0.05)$. Data are represented as mean $\pm \mathrm{SD}$ for 3 animals per group.

\section{Conclusion}

Thus, high antioxidant activity of $R$. obtusifolius seed extracts was revealed. GS/MS analysis of $R$. obtusifolius seed methanol extracts allowed identification of several compounds, which could have high contribution on biological activities. On the other hand, it was shown that the sub-cytotoxic concentration of investigated extract was quite low $\left(10 \mathrm{mgmL}^{-1}\right)$ on Murine microglial BV-2 WT cells. The ethanol extract of $R$. obtusifolius seeds revealed hypoglycemic activity, improved lipid profile in hyperglycemia induced by immobilization stress in rabbits. Further investigations should be performed to clarify the mechanisms of action. These findings suggest that $R$. obtusifolius extracts could be source of new biologically active compounds and might be recommended for treatment of diabetes mellitus.

\section{References}

1. M. Ginovyan, M. Petrosyan, A.Trchounian, BMC Complement. Altern. Med.,17, pp. 1-9 (2017)

2. N. Sahakyan, M. Petrosyan, I. Koss-Mikołajczyk, A. Bartoszek, T. Gabour Sad, M.J Nasim., M.Vanidze, A. Kalandia, C. Jacob, A. Trchounian, " Free Radic. Res., pp. 1-10 (2019)

3. Aghajanyan A, Movsisyan Z, Trchounian A., Biomed Res. Int., 2017, Article ID 9251358, pp. 1-6 (2017)

4. N. Sahakyan, A. Bartoszek, C. Jacob, M. Petrosyan, A. Trchounian, Curr. Pharmacol. Reports, 6, pp. 131136 (2020)

5. R. Apak, S. Gorinstein, V. Böhm, K.M. Schaich, M. Özyürek, K. Güçlü, Pure Appl. Chem., 85, 5, pp. $957-$ 998 (2013)

6. R.J. Ruch, S.J. Cheng, J.E. Klaunig, Carcinogenesis, 10, pp. 1003-1008 (1989)

7. M.N. Alam, N.J. Bristi, M. Rafiquzzaman, Saudi Pharm. J., 21, pp. 143-152 (2013)

8. Kulisic T, Radonic A, Katalinic V, Milos M. Food Chem., 85, pp. 633-40 (2013)

9. A.B. Abdel-Naim, A.A. Alghamdi, M.M. Algandaby, F.A. Al-Abbasi, A.M. Al-Abd, B.G. Eid, H.M. 
Abdallah, A.M. El-Halawany " Oxid. Med. Cell. Longev., 2018, Article ID 5106469, pp. 1-10 (2018)

10. A. Avetisyan, A. Markosian, M. Petrosyan, N. Sahakyan, A. Babayan, S. Aloyan, " BMC Complement. Altern. Med., 17, pp. 1-8 (2017)

11. S.M. Lim, S.H. Park, N. Sharma, S.S. Kim, J.R. Lee, J.S. Jung, H.W. Suh, Brain Res. Bull., 124, pp. 116122 (2014)

12. P. Trinder, " Ann. Clin. Biochem., 6, pp. 24-27 (1969)

13. W.T. Friedwald, R.I. Leve, D.S. Clin. Chem., 18, pp. 499-502 (1972)
14. M. Ginovyan, A. Ayvazyan, A. Nikoyan, L. Tumanyan, A. Trchounian, Curr. Microbiol. (2020)

15. M. Ginovyan, A. Trchounian, J. Appl. Microbiol., 127, pp. 472-480 (2019)

16. M. Sermakkani, V. Thangapandian, Asian J. Pharm. Clin. Res., 5, pp. 90-94 (2012)

17. B.T.S. Yff, K.L. Lindsey, M.B. Taylor, D.G. Erasmus, A.K. Jäger, " J. Ethnopharmacol., 79, pp. 101-107 (2002) 